\title{
Tensiones y resistencias en tiempos de Covid-19 en Guatemala: el papel de las organizaciones Sociales
}

Tensões e resistências em tempos de Covid-19 na Guatemala: o papel das organizações sociais

Tensions and resistence in times of Covid-19 in Guatemala: the role of social organizations

Julia Arely Arévalo Caridad ${ }^{1}$, Johanna Elizabeth Rodríguez Rojas², Maritza

Velásquez Estrada ${ }^{3}$, Edgar Antonio De León Juárez ${ }^{4}$, Cristian David Osorio

Figueroa ${ }^{5}$

\section{Introducción}

La pandemia por SARS-Cov2 llegó a Guatemala el 13 de marzo de 2020(1), las medidas indicadas como eficaces por la Organización Mundial de la Salud comenzaron a ser implementadas: el distanciamiento físico, medidas de higiene básica y la permanencia en el hogar. Este país caracterizado por ser multiétnico y pluricultural conformado por los pueblos maya, xinka, garífuna y mestizo crean un mosaico multilingüe con 25 idiomas y múltiples formas producción y consumo de alimentos entremezclándose con prácticas ancestrales.

Esta fortuna se ve opacada por desigualdades e inequidades históricas por género, etnia, clase, identidad sexual y altos índices de desnutrición crónica. A pesar de existir un marco legal para la garantía del derecho a la alimentación, el $43.6 \%$ de la población vive en inseguridad alimentaria moderada a grave ${ }^{(2)}$. Simultáneo al avance de la pandemia, la tormenta tropical Amanda dejaba a 469 mil personas afectadas, e iniciaba el período de hambre estacional en el Corredor Seco. En mayo de 2020, la desnutrición en menores de 5 años aumentó 2.52 veces, respecto al $2019^{(3)}$.

\footnotetext{
${ }^{1}$ Movimiento jóvenes de la calle (MOJOCA), Guatemala. E-mail: jarelyarec@gmail.com

${ }^{2}$ Comedor Solidario Fe. Guatemala. E-mail: produccionnimtv@gmail.com

${ }^{3}$ Asociación de trabajadoras del hogar a domicilio y de maquila (ATRADHOM). Guatemala. E-mail: coordinacion@atrahdom.org

${ }^{4}$ Organización Trans Reinas de la noche, OTRANS-RN. Guatemala. E-mail: eajuarez94@gmail.com

5 Instituto de Salud Colectiva (ISC), Universidade Federal da Bahia (UFBA). Bahia, Brasil. E-mail: drcrisdosoriofigueroa@gmail.com
} 
Las medidas eficaces en otros países, en Guatemala, exacerbaron las inequidades y dejaron a flor de piel la ausencia de protección social. En particular del derecho a la salud, empleo y hogar, con adecuación cultural y equidad de género. La población en situación de calle, mujeres, trabajadoras domésticas, población infantil y de la tercera edad fueron de los grupos que vieron sus derechos vulnerados. Enfatizándose esa vulnerabilidad en los pueblos mayas.

El objetivo del presente texto es visibilizar a partir de narrativas de organizaciones comunitarias como las disposiciones por autoridades formales pudieron agudizar el hambre y la vulnerabilidad social, económica, política y simbólica de grupos históricamente marginalizados. Además, la manera en la que lograron resistir reivindicando la dignidad de las poblaciones atendidas. Para lograrlo se presenta la experiencia de trabajo con personas viviendo en situación de calle por medio del Movimiento de Jóvenes de la Calle (Mojoca), el Comedor Solidario Fe en San Pedro la Laguna y la Asociación de Trabajadoras del Hogar a Domicilio y de Maquila (Atrahdom), quien por medio de historias de sus afiliadas muestra como se ve materializada la situación de vulnerabilidad social en la dinámica familiar e individual.

\section{Organizaciones sociales desde y para poblaciones vulnerables, ante un Estado ausente}

El Movimiento de Jóvenes de la Calle (Mojoca) fundado en 1993, apoya a las personas a abandonar las peligrosas calles de Guatemala y construir una vida estable e independiente. La captación de personas se realiza por medio del trabajo directo en la calle, impartiendo talleres y apoyando en mejorar sus condiciones de higiene y salud. Aquellas personas interesadas pueden acudir a la sede durante las mañanas teniendo el derecho a ducharse, alimentarse y conocer e involucrarse en las diversas actividades.

Brinda acceso a educación formal por medio de un programa de becas y los Talleres Solidarios Mojoca. Así como a empleo e ingresos en una cafetería y la venta de productos artesanales. Posee un hogar de transición llamado Casa Ocho de Marzo para mujeres jóvenes y madres solteras. Provee atención psicológica, sanitaria, colectivos de autoayuda y apoyo para tramitar documentos legales. 
Atiende a cerca de 400 personas incluyendo menores, mujeres privadas de libertad y personas que ya no se encuentran en situación de calle. Las personas que participan en las actividades reciben tres tiempos de alimentación balanceada.

Mientras tanto, a 179.4 kilómetros de la ciudad de Guatemala se encuentra el municipio de San Pedro La Laguna en el departamento de Sololá, perteneciente al pueblo Maya Tz'tujil. Las actividades turísticas junto a la agricultura representan las principales actividades económicas. Cada año las cosechas de maíz y frijol son guardadas por las personas agricultoras tanto para la venta como para el consumo de toda la familia.

A pesar de dichas actividades ser importantes para la alimentación en las ciudades, las comunidades mayas son las que presentan las mayores tasas de desnutrición y pobreza en el país. De esta forma, con participación comunitaria nace el Comedor Solidario Fe. Su objetivo es garantizar la alimentación saludable en infantes con riesgo de desnutrición y personas de la tercera edad de las áreas marginadas del municipio. Adicionalmente, facilita acompañamiento psicológico.

En 2008, un grupo de mujeres se organizaron para conformar la Asociación de Trabajadoras del Hogar a Domicilio y de Maquila (Atrahdom) con el objetivo de promover y defender los derechos humanos, laborales y, por ende, a la alimentación de mujeres trabajadoras de Guatemala y sus familias.

Atrahdom busca espacios de interlocución, incidencia e investigación para promocionar los derechos y obligaciones laborales establecidas en la normativa nacional e internacional. Un ejemplo de ello es su participación como la representación sindical en la Instancia Nacional de Consulta para la Política de Seguridad Alimentaria y Nutricional (INCOPAS), en la que participan junto a otras organizaciones sociales.

\section{Retos y embates: políticas públicas en contexto pandémico y el rostro de múltiples voces}

Las principales medidas adoptadas por el gobierno para evitar la propagación del COVID-19 incluyeron: el decreto de un estado de excepción, determinación del toque de queda, suspensión del transporte público y movilización intermunicipal, 
suspensión de clases en las escuelas y cierre temporal de negocios no esenciales y de la economía informal. En algunos casos, incluyendo mercados de venta de verduras y frutas en plazas abiertas, conocidos como mercados cantonales.

Para Mojoca, la suspensión de actividades no esenciales obligó a interrumpir todas las acciones presenciales. Muchas de las personas beneficiarias del movimiento se dedicaban a actividades de comercio informal, por lo que su capacidad económica se vio limitada. De estas, el $60 \%$ son mujeres en situación de pobreza; algunas realizaban trabajo doméstico por horas o días, y también perdieron esos ingresos. Para remediarlo, iniciaron micronegocios de venta ambulante de comida preparada y/o golosinas, aumentado su riesgo de exposición.

En el municipio de San Pedro La Laguna, la prohibición intermunicipal vedó el ingreso de la agricultura familiar encargada de surtir de vegetales frescos al municipio. Además, el $90 \%$ de los restaurantes, hoteles y agencias de viaje cerró sus instalaciones causando pérdidas de ingresos económicos para cientos de familias que sobreviven del turismo, aumentando el riesgo de desnutrición y pobreza.

De los relatos rescatados por Atrahdom, mujeres que habían dejado el trabajo del hogar para continuar sus estudios, se vieron obligadas a retomarlo. En algunos casos, bajo la condición de no salir de la casa donde trabajan, sin poder visitar a sus familias, aumentando la carga laboral, sin días de descanso, aumento salarial o actividades para distraerse. Relataron que sus familiares, sin ingresos económicos suficientes, deben adquirir sus alimentos en los supermercados a precios más altos y sin la frescura que los mercados cantonales proveían antes de su cierre. La ausencia del transporte público obligó a caminar largas distancias para obtener alimentos o pagar transporte privado, reduciendo el presupuesto para los alimentos. Un cambio tanto cuantitativo como cualitativo para la alimentación familiar.

La representación de Atrahdom en la INCOPAS verificó que los espacios de participación social establecidos en ley no son respetados, creando estructuras paralelas de diálogo directo con la cúpula empresarial o colocando interlocutores cuyo discurso académico no permite un diálogo de co-construcción con los sectores sociales. Asimismo, que la Instancia carece de la capacidad real de transformación de las condiciones de las poblaciones representadas. Aunque los recursos para la 
atención de la crisis existen, la mayor parte se dedica al funcionamiento y no a la inversión pública.

\section{Respuestas y resistencias de las organizaciones sociales}

Ante disposiciones estatales que no dieron cuenta de las desigualdades de la sociedad, así como de la intersección entre género, etnia y clase, la vulnerabilidad histórica de los grupos abordados se agudizó. Las políticas públicas que se esperaban como respuestas afirmativas se tradujeron en beneficios e incentivos económicos para empresas, empleadores/as y la clase media mestiza del casco urbano. Así, las organizaciones sociales reclamaron el protagonismo representando verdaderas expresiones de resistencia en respuesta a un estado ausente.

Atendiendo a las medidas sanitarias, los alimentos dejaron de servirse en el comedor de la sede. Mojoca solicitó la autorización del Ministerio de Economía para abrir su sede. Con esto iniciaron programas de recaudación, preparación y distribución de alimentos a las personas en situación de calle, se preparaban almuerzos que se repartían al medio día de forma ambulante. Para las personas beneficiarias que ya no viven en las calles se prepararon canastas básicas para su entrega mensual.

En San Pedro la Laguna, la producción agrícola familiar recobró importancia. Las mujeres fueron las principales encargadas de la distribución de los productos; tanto en mercados como desde los hogares. Diversos grupos se organizaron con el objetivo de recolectar alimentos para las personas más vulnerables en la comunidad. El Comedor Solidario Fe se organizó para la preparación y distribución de aproximadamente 150 platillos diarios que se entregaron de puerta en puerta a las familias en mayor vulnerabilidad del municipio, reduciendo el gasto diario en los hogares.

Ante la inercia institucional verificada en las instancias dedicadas al tema de seguridad alimentaria, Atrahdom se organizó para la preparación de bolsas de alimentos y productos de limpieza. Muchas mujeres trabajadoras recibieron estas bolsas que, aunque insuficientes, pretendían complementar los valores energéticos 
diarios que no conseguían completar por la limitación de ingresos y el alza de precios de los productos.

\section{Reflexiones finales}

Los movimientos sociales representan formas de resistencia ante un sistema que no considera las diferencias. La ausencia de espacios de diálogo para la construcción de soluciones por parte del Estado se comprueba con decisiones insensibles para sectores vulnerables. Las políticas responden a un sector minoritario y privilegiado de la población, invisibilizando tensiones entre clase, etnia y sexo. Estas narrativas permiten revalorizar y dignificar la vida en comunidad, la importancia de la participación social y proponen una lucha resistente y resiliente por el bien común.

Los esfuerzos intersectoriales, la exigibilidad de derechos y las nuevas dinámicas de asociación, expresión y manifestación en el contexto pandémico y de estados de excepción, representan formas novedosas de hacer democracia. Además, invitan a pensar en el importante papel de las ciudadanías, en especial en contextos plurales y diversos como Guatemala para garantizar condiciones dignas de vida.

\section{Referencias}

1. Departamento de Epidemiología. Boletín de la semana epidemiológica número 11. Guatemala; 2020.

2. FAO, OPS, WFP, UNICEF. Panorama de la seguridad alimentaria y nutricional en América Latina y el Caribe 2019. Santiago: FAO, OPS, WFP y UNICEF; 2019 [Cited 2020 mar 25]. Available from: http://www.fao.org/publications/es

3. Oficina de la Coordinadora Residente y la Oficina para la Coordinación de Asuntos Humanitarios. Guatemala COVID-19: Informe de situación No. 05. Guatemala; 2020. 